\title{
Stroke: an ongoing revolution
}

\author{
AVC: uma revolução em curso
}

Groundbreaking results about ischemic stroke (IS) treatment worldwide were published within the last year. In a recent editorial, the International Journal of Stroke $\mathrm{l}^{1}$ reported that over the last two decades of stroke research only two findings really changed case-fatality and functional dependence of IS survivors: the first was the seminal paper "Stroke Unit Trialists",published by Peter Langhorne in 1997, when it became clear that stroke units not only save lives but also reduce functional dependence. The second was the discovery of intravenous use of tissue plasminogen activator (tPA) for hyperacute stroke reperfusion in 1995. These breakthroughs buried the nihilist approach to stroke and changed the paradigm of IS treatment worldwide. The emergence of neurohospitalists as crucial professionals for inpatient care has become a reality. However, intravenous thrombolysis is less able than desirable, to open large vessels such as the internal carotid artery or proximal branches of the middle cerebral artery. In the last 10 years, many randomized clinical trials (RCT) of thrombectomy were "negative". After December 2014, five new randomized controlled trials showed that intra-arterial treatment combined with IV lysis was more effective than IV lysis alone, leading to absolute improvements in functional independence ranging from 13.5 to $31 \%$ at 3 months after treatment ${ }^{2,3,4,5,6}$.

Like patients with myocardial infarctions, more IS patients who arrive early at hospitals should now be offered more effective acute treatments. These results framed a new and defiant landscape for neurologists. How many Brazilians stroke centers are prepared to incorporate this new research evidence in their daily clinical practice? How much infrastructure do we need in our programs to teach new skills required for endovascular treatment, for stroke and neuroradiology residents? Do we have enough stroke units to care for patients, whether or not they are submitted to endovascular therapy?

Social aspects increase the complexity of these questions. Life expectancy puts more pressure on the burden of IS treatment, because it enlarges the angle at the top of our demographic pyramid, and increases the probability of bigger IS incidences in this age-strata. We have been observing an increase of stroke incidence in the oldest-old patients in the Joinville Stroke Register over the past 20 years. For sure, we are going to see more patients with IS.

In the setting of great advances in acute stroke care, a new tool that can help set the stage to decrease stroke incidences has been developed. The Stroke Riskometer app calculates the 5- and 10-year risk of stroke. This tool can enhance primary and secondary stroke prevention capabilities. All data can be saved, be compared over time and also offer practical tips of lifestyle changes. Developed by Prof. Valery Feigin, from Auckland University this app is a candidate to win a world contest among 100,000 other mobile health applications.

App users will have the ability to voluntarily consent to participate in the Stroke Riskometer-based RIBURST (Reducing International Burden of Stroke Using Mobile Technology). We would like to invite you to participate in the RIBURST study. Results will be encrypted and stored in a secure database. Participants will be reminded to retake the questionnaire after 12 months, via push notifications and e-mail prompts. The app download (available for i-phone and android) as well as participation in the study, are free. Knowing one's risk can be a powerful tool to enhance healthy lifestyles and control of risk factors for vascular disease. Despite the enormous advances in the field of acute IS treatment, the most effective gun in the battle remains... preventing IS from happening.

Norberto Cabral ${ }^{1}$, Adriana B. Conforto ${ }^{2,3}$

\footnotetext{
${ }^{1}$ Universidade da Região de Joinville, Joinville SC, Brazil;

${ }^{2}$ Universidade de São Paulo, Faculdade de Medicina, Hospital das Clínicas, Sao Paulo SP, Brazil;

${ }^{3}$ Hospital Israelita Albert Einstein, Sao Paulo SP, Brazil.

Correspondence: Norberto Cabral; Univille; R. Paulo Malschitzki, 10; 89219-710 Joinville SC, Brasil; E-mail: cabral@neurologica.com.br

Conflict of interest: There is no conflict of interest to declare.

Received 07 July 2015; Accepted 28 July 2015.
} 
1. Donnan GA. Endovascular therapy: the dawning of a new era. Int J Stroke. 2015;10(4):463. doi:10.1111/ijs.12514

2. Berkhemer OA, Fransen PS, Beumer D, Berg LA, Lingsma HF, Yoo AJ et al. A randomized trial of intraarterial treatment for acute ischemic stroke. $\mathrm{N}$ Engl J Med. 2015;372:11-20. doi:10.1056/NEJMoa1411587

3. Goyal M, Demchuk AM, Menon BK, Eesa M, Rempel JL, Thornton $J$ et al. ESCAPE Trial Investigators. Randomized assessment of rapid endovascular treatment of ischemic stroke. N Engl J Med. 2015;372(11):1019-30. doi:10.1056/NEJMoa1414905

4. Campbell BC, Mitchell PJ, Kleinig TJ, Dewey HM, Churilov L, Yassi N et al. Endovascular therapy for ischemic stroke with perfusion-imaging selection. N EnglJ Med. 2015;372(11):1009-18. doi:10.1056/NEJMoa1414792
5. Saver JS, Goyal M, Bonafe A, Diener H, Levy E, Mendes-Pereira VM, et al. Stent-retriever thrombectomy after intravenous t-PA vs. t-PA alone in stroke. N Engl J Med. 2015;372(24):2285-95. doi:10.1056/NEJMoa141506

6. Jovin TG, Chamorro A, Cobo E, de Miquel MA, Molina CA, Rovira A et al. Thrombectomy within 8 hours after symptom onset in ischemic stroke. N Engl J Med. 2015;372:2296-2306. doi:10.1056/NEJMoa1503780

7. Feigin VL, Krishnamurthi R, Bhattacharjee R, Parmar P, Theadom A, Hussein et al New strategy to reduce the global burden of stroke. Stroke. 2015;46:1740-7. doi:10.1161/STROKEAHA.115.008222 